BMJ Open

Sport \&

Exercise

Medicine

\title{
Asia-Pacific consensus on physical activity and exercise in pregnancy and the postpartum period
}

\author{
Ryan Lee, ${ }^{1}$ Serene Thain, ${ }^{1}$ Lay Kok Tan, ${ }^{1}$ Terry Teo (D) , ${ }^{2}$ Kok Hian Tan, ${ }^{1}$ IPRAMHO \\ Exercise in Pregnancy Committee
}

To cite: Lee R, Thain S, Tan LK, et al. Asia-Pacific consensus on physical activity and exercise in pregnancy and the postpartum period. BMJ Open Sport \& Exercise Medicine 2021;7:e000967. doi:10.1136/ bmjsem-2020-000967

LKT and KHT are joint senior authors.

Accepted 7 May 2021

\section{Check for updates}

C) Author(s) (or their employer(s)) 2021. Re-use permitted under CC BY-NC. No commercial re-use. See rights and permissions. Published by BMJ.

${ }^{1}$ Department of Maternal Fetal Medicine, KK Women's and Children's Hospital, Singapore ${ }^{2}$ Department of Obstetrics and Gynaecology, KK Women's and Children's Hospital, Singapore

\section{Correspondence to}

Prof Kok Hian Tan, Department of Maternal Fetal Medicine, KK Women's \& Children's Hospital, Singapore, Singapore;

tan.kok.hian@singhealth.com.sg

\section{ABSTRACT}

Physical activity and exercise in pregnancy are generally beneficial and enhance the physical and mental health of women. These benefits also prevent excessive weight gain and reduce risks of obesity in pregnancy, such as gestational diabetes, hypertensive disorders, higher rates of caesarean delivery, macrosomia and stillbirth. Thus, there is a need to optimise perinatal exercise and physical activity globally. There is currently no consensus recommendation on the role of physical activity and exercise in pregnancy and the postpartum period in the Asia-Pacific region. In this paper, we present seven key consensus recommendations on physical activity and exercise in pregnancy and the postpartum period by 18 key members representing 10 countries in Asia-Pacific regions during an international workshop of the Asia Diabetes in Pregnancy Conference in Singapore on 11-12 January 2020. Through these consensus recommendations, we hope to improve the metabolic health of pregnant women living in Asia-Pacific regions by educating the public and guiding healthcare professionals on the safety and importance of physical exercise and activity to benefit pregnant women and after childbirth.

\section{INTRODUCTION}

Physical activity is defined as any bodily movement produced by the contraction of skeletal muscles, while exercise is defined as physical activity consisting of planned, structured and repetitive body movements. ${ }^{1}$ Physical activity comprises a spectrum of movement behaviours, including moderate to vigorous physical activity (MVPA). ${ }^{2}{ }^{3}$ Physical activity is associated with immense health benefits such as improvements in physical fitness, mental health, decreased risk of chronic disease, resulting in significant morbidity and mortality. ${ }^{1}$ Physical activity in pregnancy has also been shown to optimise maternalfetal health for better outcomes. ${ }^{4-6}$ These benefits include decreased caesarean births and operative vaginal delivery, postpartum recovery and prevention of depression in the postpartum period. ${ }^{7-9}$ On the contrary, a lack of physical activity and exercise is associated with maternal and fetal adverse outcomes. These include pregnancy complications such as gestational diabetes mellitus (GDM), preeclampsia, gestational hypertension and fetal macrosomia due to rising maternal obesity. ${ }^{10-12}$

Physical activity and exercise are integral components of lifestyle behaviours that help pregnant women moderate their body mass index (BMI) and gestational weight gain (GWG). Studies showed that excessive GWG increases the risk of delivery by caesarean section, postpartum weight retention and having a high birth weight baby. ${ }^{13-15}$ Lifestyle interventions including diet, physical activity and behavioural changes may reduce these risks by prevention excessive weight gain. The optimal body mass for Asian adults differs from Caucasian populations. ${ }^{16}$ A recent Asian study defined the optimal GWG by prepregnancy BMI category to be $19.5 \mathrm{~kg}$ for underweight, $13.7 \mathrm{~kg}$ for normal weight, $7.9 \mathrm{~kg}$ for overweight and $1.8 \mathrm{~kg}$ for obese women, respectively. ${ }^{17}$ Hence, appropriate weight management using physical activity for overweight and women with obesity before, during and after pregnancy is important.

After pregnancy, physical activity and exercise may be resumed gradually in the postpartum period as soon as medically safe, depending on the mode of delivery and the presence of any complications. ${ }^{2} 3$ For example, women with extensive perineal tears during their delivery may suffer from urinary incontinence that may be a barrier to exercise. ${ }^{18}$ After delivery, postnatal women may require adequate time to heal and regain strength, particularly in the abdominal and pelvic floor muscles. ${ }^{19}$ Hence, it is paramount for healthcare professionals to recommend and reinforce healthy lifestyles in women in the postpartum period as their level of participation in exercise decreases after giving birth. $^{2021}$ 
The evidence for relevant consequences of lifestyle, diet and growth patterns in early life on later health and disease risk is strong. There is a need to optimise perinatal exercise and activity for the affluent populations in Europe and the world, especially for the nonaffluent population in Asia. This can contribute to the primary prevention of global obesity and diabetes, both epidemics prevalent, especially in Asia-Pacific regions. It is important to drill down to simpler recommendations globally, such that healthcare practitioners and patients can follow and use them.

There is currently no consensus recommendation on the safety and roles of physical activity and exercise in pregnancy and the postpartum period in the AsiaPacific region. Hence, we aim to develop an Asia-Pacific Consensus on Physical Activity \& Exercise in Pregnancy. Our objective for these recommendations is to provide guidance on physical activity for pregnant women during the antenatal and postpartum period and encourage healthy lifestyles to achieve better pregnancy outcomes.

\section{METHODS}

We held an annual Asia Pacific Diabetes in Pregnancy Conference and an Integrated Platform for Research in Advancing Metabolic Health Outcomes of Women and Children (IPRAMHO) Asia-Pacific workshop for the last 3 years, which gathers expertise from different countries to review the progress of joint multicentre research effort in GDM. ${ }^{22}$ Our group of Asia-Pacific healthcare practitioners met on 10 and 11 January 2020 in KK Women's and Children's Hospital, Singapore, to discuss GDM, obesity, and focused on the benefits of physical activity in pregnancy and after childbirth.

The Asia-Pacific consensus on physical activity and exercise in pregnancy and the postpartum period were developed according to the Appraisal of Guidelines for Research and Evaluation (AGREE) II instrument ${ }^{23}$. The AGREE II instrument was independently assessed by two assessors to appraise and compare recommendations among the clinical guidelines. Domain scores were considered of sufficient quality when $>60 \%$ and of good quality when $>80 \%$. The highest scoring AGREE II domain was 'scope and purpose' (100\%), followed by 'rigour of development' (97\%), 'rigour of development' $(97 \%)$, 'applicability' (88\%), 'clarity of presentation' $(86 \%)$ and 'stakeholder involvement' $(69 \%)$. The overall guideline quality was $93 \%$ with recommendations for use.

The consensus statements were derived after going through a thorough literature review by conducting an electronic search on the keywords including 'physical activity', 'exercise', 'pregnancy' and 'postpartum' through Medline, PubMed, Cochrane database of systematic reviews on the literature from 1985 to December 2019. Studies identified included systematic reviews, meta-analysis, randomised control trials and observational studies. Outcomes include all articles related to maternal physical activity during pregnancy and the postpartum period on maternal, fetal, neonatal morbidity or mortality.

The background literature review was conducted by 5 members of the committee, which consists of a total of 18 members of the IPRAMHO group. The IPRAMHO group consists of obstetricians, nurses, physiotherapists and sports medicine physicians from 10 countries (Singapore, Malaysia, Thailand, Myanmar, India, Indonesia, Vietnam, China, Sri Lanka and Australia). Results were limited to English language materials. Areas that lacked scientific research evidence relied on best practice based on expert opinion of the IRPAMHO group. Ethics approval was exempted as this was a consensus opinion workshop among members of the IPRAMHO group. All participants gave informed verbal consent before taking part in the workshop.

At the consensus workshop, questions and statements relating to physical activity and exercise in pregnancy were posted. Answers to the questions include 'yes', 'no', 'maybe' and 'no comments'. An electronic clicker system was used to collect the responses to the questions that were recorded. There were active discussions on the responses posted, and these responses were debated among the 18 members of the IPRAMHO group.

Following these discussions, the key consensus recommendations on physical activity and exercise in pregnancy were voted and agreed on by expert opinion after looking at the empirical evidence with voting responses threshold above $75 \%$ met to be accepted as a recommendation for the consensus statements. A draft consensus was then worked out and circulated among the members for agreement before the final consensus document was agreed at the end of the meeting.

\section{CONSENSUS STATEMENTS}

\section{Physical activity is beneficial and should be encouraged} during and after pregnancy

Pregnant women can be reassured about the safety of physical activity by highlighting the benefits and lack of harm in uncomplicated pregnancies. The benefits of exercise in pregnancy include a higher incidence of vaginal delivery and lower incidence of excessive weight gain, gestational diabetes, hypertension, caesarean deliveries and low birth weight. ${ }^{245}$ Conversely, physical activity in uncomplicated pregnancies is not associated with miscarriage, stillbirth, fetal anomalies, preterm birth, preterm prelabour rupture of membranes or neonatal death. ${ }^{7} 1011$ 24-26

Physical activity comprises a spectrum of movement behaviours, including MVPA. ${ }^{23}$ Moderate-intensity exercises can be defined as $40 \%-59 \%$ heart rate reserve (HRR), while vigorous intensity is defined as $60 \%-80 \%$ HRR. ${ }^{27}$ There is currently less evidence to support that light physical activity is beneficial compared with MVPA. ${ }^{3}$ A recent meta-analysis showed that vigorous-intensity exercise completed even into the third trimester appears to be safe with no significant differences in small for gestational age, low birth weight or prematurity. ${ }^{28}$ 
Pregnant women with certain medical conditions should consult their healthcare providers early before commencing exercise

It was previously shown that women with absolute contraindications might continue activities of daily living and not participate in strenuous exercise. In contrast, women with relative contraindications should be cautious and discuss the risks and benefits of MVPA with their physicians before participating in exercise programmes. ${ }^{2}{ }^{29}$ Recently, Meah et alshowed that most of these contraindications are based on expert opinion and may be outdated with new evidence found on the benefits of prenatal exercise ${ }^{30}$ Furthermore, Meah et al identified conditions with absolute contraindications to MVPA and disorders with relative contraindications with modifications to MVPA. ${ }^{30}$

Absolute contraindications to exercise with the potential for harmful effects for mothers and/or fetuses include $^{30}$

- Severe respiratory diseases.

- Severe acquired or congenital heart disease with exercise intolerance.

- Uncontrolled or severe arrhythmia.

- Placenta abruption.

- Vasa previa.

- Uncontrolled type 1 diabetes.

- Intrauterine growth restriction.

- Active preterm labour.

- Severe preeclampsia.

- Cervical insufficiency.

Relative contraindications with modifications of FITT (frequency, intensity, time and type ${ }^{31}$ instead of complete cessation of physical activity include ${ }^{30}$

- Mild respiratory disorders.

- Mild congenital or acquired heart disease.

- Well-controlled type 1 diabetes.

- Mild pre-eclampsia.

- Preterm premature rupture of membranes.

- Placenta previa after 28 weeks.

- Untreated thyroid disease.

- Symptomatic severe eating disorder.

- Multiple nutrient deficiencies/malnutrition.

- Moderate to heavy smoking (>20 cigarettes per day).

Furthermore, the following conditions below are no longer considered contraindications based on empirical evidence where pregnant women can benefit from prenatal physical activity ${ }^{30}$

- Chronic hypertension.

- Gestational hypertension.

- Overweight or obese women.

- Recurrent miscarriage.

- Short cervix.

- Multiple pregnancies.

- Epilepsy.

- Anaemia

- Orthopaedic limitations.

- History of a sedentary lifestyle, preterm labour or fetal growth restriction.
Physical activity is safe for pregnant women and their fetuses in the absence of any contraindications

Physical activity in pregnancy is safe and pregnant women should be encouraged to continue or initiate safe physical activities. ${ }^{62930}$ All women without contraindications should remain physically fit throughout pregnancy. ${ }^{30}$ The benefits of exercise include improved cardiorespiratory fitness, ${ }^{1}$ enhanced psychological well-being, ${ }^{9}$ reductions in excessive GWG, prevention of obesity and its associated increased maternal adverse outcomes including gestational diabetes, preeclampsia, caesarean section rates and postpartum weight gain. ${ }^{710} 14$

Physical activity is paramount in the optimisation and maintenance of healthy lifestyles in pregnancy. In particular, pregnant women with obesity should be encouraged to engage in physical activity with healthy lifestyle modifications. There is currently strong evidence suggesting an inverse association between physical activity and excess GWG ${ }^{32}{ }^{33}$ High GWG has also been associated with fetal macrosomia and neonatal adiposity. ${ }^{34} \mathrm{~A}$ systematic review and meta-analysis by the International Weight Management in Pregnancy Collaborative Group showed that physical activity reduces GWG (OR $-0.7 \mathrm{~kg}$, CI 0.92 to $-0.48, \mathrm{I}^{2}=14.1 \%, 33$ studies, 9320 women) and lowers the odds of caesarean section (OR 0.91, CI 0.83 to 0.99, $\mathrm{I}^{2}=0 \%, 32$ studies, 11410 women) with no evidence that this effect differs across subgroups defined by maternal characteristics. ${ }^{35}$ Conversely, Muktabhant $e t$ al examined the relationship between physical exercise in pregnancy and 'low' or insufficient GWG where women with a normal $\left(18.5-24.9 \mathrm{~kg} / \mathrm{m}^{2}\right)$ BMI had a greater chance of 'low' weight gain compared with the nonexercising control group with no adverse outcomes. ${ }^{36}$ Exercise has shown to result in a modest decrease in overall weight gain $(1-2 \mathrm{~kg})$ in normal weight, overweight and obese women. ${ }^{36}$ 37 Throughout pregnancy, resting energy expenditure increases to meet the metabolic demands of the fetus. ${ }^{38}$ Currently, the peak aerobic capacity of muscle defined as maximal oxygen uptake (VO2 max) is considered the gold standard measurement of aerobic fitness. ${ }^{39}$ Resting VO2 progressively increases from $16 \%$ to $32 \%$ in pregnant women compared with nonpregnant women to meet the metabolic demands of the fetus. ${ }^{4041}$ The defined target heart rate zones based on age and the appropriate fitness levels can be used safely in healthy pregnant women. ${ }^{39}$ In particular, prenatal exercise increases VO2 max in women with obesity. ${ }^{43}$ Validated heart ranges for sedentary, overweight and obese pregnant women are from $102 \mathrm{bpm}$ to $124 \mathrm{bpm}$ (20-29 years of age) and from $101 \mathrm{bpm}$ to $120 \mathrm{bpm}$ (30-39 years of age), representing an exercise intensity of $20 \%-39 \%$ VO2 reserve, which is recommended for previously sedentary pregnant women to exercise safely in pregnancy. ${ }^{42}$

Anatomical and physical changes in pregnancy include increased weight gain, a forward shift in the centre of gravity and accentuated lumbar lordosis, which may cause low back pain. ${ }^{44}$ Cardiac output, heart rate and stroke volume increase in pregnancy to provide 
adequate circulatory reserves for pregnant mothers and fotuses. ${ }^{45-47}$ Cardiac output in mid pregnancy increases by $30 \%-50 \%{ }^{48}$; heart rate increases by $20 \%$ in the second and third trimester ${ }^{45}$ and stroke volume increases by $10 \%$ at the end of the first trimester. ${ }^{46}$

Although physical activity is generally safe, pregnant women are encouraged to be physically assessed by healthcare providers before embarking on and continuing physical activity. For example, previously inactive women are encouraged to start physical activity at a lower intensity and gradually increasing the duration and intensity as their pregnancy progresses. ${ }^{29}$ Also, the PARmed-X for pregnancy developed by the Canadian Society for Exercise Physiology in 2015 serves as a checklist for healthcare providers to evaluate and assess pregnant women before participating in exercise. ${ }^{49}$

The American College of Sports Medicine (ACSM) also recommends preparticipation screening to identify women requiring medical clearance from physicians before initiating exercise or adjusting their exercise regimes and identifying individuals with health contraindications to stop participating in exercise programmes for their safety. ${ }^{50}$ Although discussion with a healthcare professional is encouraged, delaying or ceasing exercise before the consultation can have adverse effects on health outcomes, especially if they gain excessive weight early in the first trimester, which is associated with adverse maternal and fetal outcomes. ${ }^{10-12}$ Hence, it should be ideal but not necessary for pregnant women to delay exercising be screened by professionals to be medically fit safe before participating and continuing physical activity. ${ }^{29}$

\section{Pregnant women with no contraindications should aim to accumulate at least $\mathbf{1 5 0}$ min of moderate-intensity physical activity each week}

Pregnant women should accumulate at least $150 \mathrm{~min}$ of moderate-intensity physical activity each week to achieve health benefits and reduce pregnancy complications. ${ }^{2}{ }^{29}$ Physical activity should also be accumulated over a minimum of 3 days per week, although being active daily is also encouraged because the benefits of exercising outweigh potential harms. ${ }^{29}$

Physical activity comprises light, moderate and vigorous intensity activities. Moderate to vigorous intensity exercises have been shown to have greater benefits compared with light intensity ones. ${ }^{29}$ Light intensity exercise includes gentle walking and activities of daily living. ${ }^{30}$ MVPA should incorporate a variety of aerobic and resistance training activities for greater benefits. ${ }^{50}$ Examples of moderate-intensity aerobic physical activity include brisk walking, swimming, stationary cycling, low-impact aerobics, jogging, modified yoga and modified Pilates. ${ }^{2}$ Examples of resistance training activities include bodyweight exercises such as squats, lunges and push-ups; exercises with light dumbbells/weights and resistance band exercises. ${ }^{2}$
Aerobic exercise can be safely initiated in the first trimester, lasting approximately $30-60 \mathrm{~min}$ at least $3-4$ times (up to daily) per week until delivery. ${ }^{14}{ }^{15}$ Progression of activity can be done by gradually increasing the frequency of sessions in a week, duration of each session or intensity of each session (within the appropriate target heart rate or rating of perceived exertion (RPE)). ${ }^{42} 43$ The rate of progression should be more gradual in those who are highly inactive and/or unfit.

\section{Pregnant women should take safety precautions while exercising}

Temperature regulation is highly dependent on hydration and environmental conditions. ${ }^{29}$ Pregnant women should aim to stay well hydrated before and after exercise. Staying in a cool environment, wearing loose-fitting clothing and avoiding exercise in excessively warm weather is recommended, ${ }^{1}$ although exercise, in general, would not be expected to increase core body temperature into the range of concern. ${ }^{51}$ Vigorous-intensity physical activity or prolonged physical activity more than $45 \mathrm{~min}$ in duration can result in hypoglycaemia in women with diabetes mellitus on insulin ${ }^{52}$ and/or dehydration. Thus, precautions such as adequate hydration, caloric intake before exercise, reducing the exercise session duration and carrying out physical activity in a cool environment should be undertaken. ${ }^{53}$ All women should perform adequate 'warm up' and 'cool down' exercises to condition major muscle groups for good posture, support and reduction of risk of injury.

The following should be avoided for safety reasons:

- hot yoga and hot Pilates due to excessive heat causing dehydration. ${ }^{54}$

- Contact sports and activities that increase the risk of falls. ${ }^{55}$

- Rapid changes in direction and bouncing during exercises increase the risk of injury. ${ }^{56}$

- Scuba diving with risk of the fetus developing compression sickness. ${ }^{57}$

- Prolonged standing with a significant decrease in cardiac output. ${ }^{58}$

- Lying supine after the first trimester while exercising while this can lead to decreased cardiac output, aortal-caval compression and hypotension. ${ }^{58}$

- Excessive abdominal exercises such as abdominal curls may lead to diastasis of the recti muscles requiring postnatal repair. ${ }^{59}$

The intensity of physical activity in pregnancy can be monitored by various means. One of these is the 'talk test', whereby the individual is considered to be doing moderate-intensity physical activity if he or she can talk but cannot sing while doing the activity. Second, RPE can also be used to determine the intensity of physical activity, with moderate-intensity physical activity corresponding to an RPE of 13-14 on the 6-20 Borg scale or $5-6$ on the $0-10$ Borg scale. ${ }^{60}$ Third, pregnant women may also consider monitoring their physical activity intensity based on target heart rate ranges for pregnant 
women. ${ }^{60}$ Women who have been habitually exercising at vigorous intensity aerobic activity before pregnancy may be able to continue these activities during pregnancy and postpartum. As heart rate predicted from RPE may be significantly underestimated during pregnancy ${ }^{61}$ women engaging in vigorous-intensity physical activity may want to monitor RPE and heart rate. Da Silva et al recently developed and cross-validated RPE ranges for light and moderate-intensity physical activity for pregnant women derived from heart rate target ranges. ${ }^{62}$ Also, pregnant women, especially athletes, should avoid exercising at an intensity greater than $90 \%$ maximum heart rate in the first and second trimester until further research can confirm its safety due to reduced mean uterine artery blood flow causing fetal distress. ${ }^{28} 63$

\section{Pregnant women with warning signs should stop exercising and seek immediate medical attention}

Pregnant women should stop exercising and seek immediate medical attention if they experience any of these signs and symptoms, including ${ }^{2964}$

- persistent and excessive shortness of breath not resolved at rest.

- Severe chest pain.

- Regular, painful contractions.

- Vaginal bleeding.

- Leaking amniotic fluid or rupture of membranes.

- Calf pain or swelling.

- Dizziness, syncope or faintness that do not resolve on rest.

\section{Physical activity should be resumed gradually after delivery in the postpartum period}

Many physiological changes of pregnancy persist for 4 to 6 weeks postpartum. Hence, physical activity can be resumed gradually after delivery as soon as certified medically safe, depending on the mode of delivery and the presence of any complications. ${ }^{2}$ Pelvic floor muscle training, which reduce the risk of urinary urge incontinence, can be initiated in the immediate postpartum period in women with uncomplicated normal vaginal deliveries and caesarean sections. ${ }^{1825}$

In the postpartum period, recovery of the levator ani muscle and associated connective tissue, nerves are generally maximised by $4-6$ months postnatal and a reflection of levator hiatus area recovery. ${ }^{19}{ }^{65}$ In addition, the abdominal fascia regained only $51 \%-59 \%$ of its original tensile strength by 6 weeks postcaesarean section and $73 \%-93 \%$ of its original tensile strength at $6-7$ months postnatal. ${ }^{66}$ Hence, It is recommended that a low impact exercise timeline be followed within the first 3 months of the postnatal period, followed by a return to running between 3 and 6 months postnatal earliest. ${ }^{67}$

In addition, abdominal strengthening exercises such as abdominal crunch exercises and the drawing-in exercise, a manoeuvre that increases abdominal pressure by pulling in the abdominal wall muscles, have been shown to decrease the incidence of diastasis recti abdominus and decrease the inter-rectus distance in postnatal women after vaginal births born by caesarean deliveries. ${ }^{59} 68$

About $10 \%$ of women experience postpartum depression, with nearly $25 \%$ still in treatment after 1 year. ${ }^{69}$ Postpartum aerobic exercises have been shown to reduce depressive symptoms in women with postpartum depression. ${ }^{9}$ Evidence has also shown that physical exercise can also reduce postpartum weight gain. ${ }^{21}$ In addition, regular aerobic exercise does not affect lactation or infant growth and can be safely continued in the postpartum period. ${ }^{70}$

\section{CONCLUSION}

These statements are used as educational aids and references for healthcare professionals in the Asia-Pacific region. They present recognised clinical methods and techniques for consideration by practitioners for incorporation into their practices in the Asia-Pacific region. We sincerely believe that the above consensus should be widely disseminated and diligently observed, as it will greatly contribute to the understanding and reduction of obesity and diabetes globally, especially in the Asia-Pacific region, to improve the metabolic outcomes of pregnant women.

Acknowledgements We would like to acknowledge the help and support of the Asia \& Oceania Federation of Obstetrics and Gynaecology, Maternal Foetal Medicine Committee (AOFOG MFM); and National Medical Research Council Integrated Platform for Research in Advancing Metabolic Health Outcomes of Women and Children (IPRAMH0) (NMRC CGAug16C008).

Collaborators The Members Of The Consensus Working Group Are: AustraliaProf Satvinder Singh Dhaliwal, Curtin University, Perth; China-Dr Zongjie Zhou, Fudan University, Shanghai; India—Dr Yash Bhanji Boricha, Mgm's University of Health Sciences, Navi Mumbai, Maharashtra; Indonesia—Dr Herman Kristanto, Rumah Sakit Columbia Asia Semarang, Semarang; Malaysia-Dr Krishna Kuma, Hospital Tuanku Ja'afar Seremban; Myanmar—Dr Swe Swe Myint, Central Women's Hospital, Yangon; Singapore - Prof Kok Hian Tan, KK Women's and Children's Hospital; Dr Tony Tan, Raffles Hospital; A/Prof Lay Kok Tan, Singapore General Hospital; Dr Ivy Lim, Changi General Hospital; Dr Serene Thain, KK Women's and Children's Hospital; Dr Ryan Lee, KK Women's and Children's Hospital; Sri Lanka—Dr Shahul Hameed Mohamed Siraj, Hospital Battacolaou; Tiran Dias, North Colombo Teaching Hospital \& University of Colombo; Thailand - Dr Dittakarn Boriboonhirunsarn, Siriraj Hospital, Mahidol University, Bangkok; Vietnam-Dr Tran Thi Lien Huong, Tu Du Hospital, Ho Chi Minh City; WHO Collaborating Centre Birmingham—Dr Shakila Thangaratinam.

Funding This study is funded by Singapore National Medical Research Council (NMRC/CG/C008A/2017_KKH) - Integrated Platform for Research in Advancing Metabolic Health Outcomes of Women and Children in Asia (IPRAMH0).

Competing interests None declared.

Patient consent for publication Not required.

Ethics approval Ethics approval was exempted as this was a consensus opinion workshop among members of the IPRAMHO group.

Provenance and peer review Not commissioned; externally peer reviewed.

Data availability statement Data are available upon reasonable request.

Open access This is an open access article distributed in accordance with the Creative Commons Attribution Non Commercial (CC BY-NC 4.0) license, which permits others to distribute, remix, adapt, build upon this work non-commercially, and license their derivative works on different terms, provided the original work is properly cited, appropriate credit is given, any changes made indicated, and the use is non-commercial. See: http://creativecommons.org/licenses/by-nc/4.0/.

ORCID iD

Terry Teo http://orcid.org/0000-0001-6736-1992 


\section{REFERENCES}

1 American College of Sports Medicine. ACSM's guidelines for exercise testing and prescription. 10th ed. Philadelphia, PA: Wolters Kluwer, 2018.

2 American College of Obstetricians and Gynecologists. ACOG Committee opinion no. 650: physical activity and exercise during pregnancy and the postpartum period. Obstet Gynecol 2015;126:e135-42.

3 US Department of Health and Human Services. 2018 physical activity guidelines Advisory Committee scientific report. Washington, DC, 2018. Available: https://health.gov/paguidelines/second-edition/ [Accessed 06 Feb 2021].

4 Ferraro ZM, Gaudet L, Adamo KB. The potential impact of physical activity during pregnancy on maternal and neonatal outcomes. Obstet Gynecol Surv 2012;67:99-110.

5 Reyes LM, Davenport MH. Exercise as a therapeutic intervention to optimize fetal weight. Pharmacol Res 2018;132:160-7.

6 Berghella V, Saccone G. Exercise in pregnancy! Am J Obstet Gynecol 2017;216:335-7.

7 Davenport MH, Ruchat S-M, Sobierajski F, et al. Impact of prenatal exercise on maternal harms, labour and delivery outcomes: a systematic review and meta-analysis. $\mathrm{Br} J$ Sports Med 2019;53:99-107.

8 Artal R. The role of exercise in reducing the risks of gestational diabetes mellitus in obese women. Best Pract Res Clin Obstet Gynaecol 2015;29:123-32.

9 Davenport $\mathrm{MH}, \mathrm{McC}$ urdy $\mathrm{AP}$, Mottola MF, et al. Impact of prenatal exercise on both prenatal and postnatal anxiety and depressive symptoms: a systematic review and meta-analysis. $\mathrm{Br} J$ Sports Med 2018;52:1376-85

10 Davenport MH, Ruchat S-M, Poitras VJ, et al. Prenatal exercise for the prevention of gestational diabetes mellitus and hypertensive disorders of pregnancy: a systematic review and meta-analysis. $\mathrm{Br} J$ Sports Med 2018;52:1367-75.

11 Davenport MH, Meah VL, Ruchat S-M, et al. Impact of prenatal exercise on neonatal and childhood outcomes: a systematic review and meta-analysis. Br J Sports Med 2018;52:1386-96.

12 Adesegun D, Cai C, Sivak A, et al. Prenatal exercise and pregestational diseases: a systematic review and meta-analysis. $J$ Obstet Gynaecol Can 2019;41:1134-43. e17.

13 Koh H, Ee TX, Malhotra R, et al. Predictors and adverse outcomes of inadequate or excessive gestational weight gain in an Asian population. J Obstet Gynaecol Res 2013;39:905-13.

14 Di Mascio D, Magro-Malosso ER, Saccone G, et al. Exercise during pregnancy in normal-weight women and risk of preterm birth: a systematic review and meta-analysis of randomized controlled trials. Am J Obstet Gynecol 2016;215:561-71.

15 Magro-Malosso ER, Saccone G, Di Mascio D, et al. Exercise during pregnancy and risk of preterm birth in overweight and obese women: a systematic review and meta-analysis of randomized controlled trials. Acta Obstet Gynecol Scand 2017;96:263-73.

16 WHO Expert Consultation. Appropriate body-mass index for Asian populations and its implications for policy and intervention strategies. Lancet 2004;363:157-63.

17 Ee TX, Allen JC, Malhotra R, et al. Determining optimal gestational weight gain in a multiethnic Asian population. J Obstet Gynaecol Res 2014;40:1002-8.

18 Nygaard I, Girts T, Fultz NH, et al. Is urinary incontinence a barrier to exercise in women? Obstet Gynecol 2005;106:307-14.

19 Stær-Jensen J, Siafarikas F, Hilde G, et al. Postpartum recovery of levator hiatus and bladder neck mobility in relation to pregnancy. Obstet Gynecol 2015;125:531-9.

20 Minig L, Trimble EL, Sarsotti C, et al. Building the evidence base for postoperative and postpartum advice. Obstet Gynecol 2009;114:892-900.

21 O'Toole ML, Sawicki MA, Artal R. Structured diet and physical activity prevent postpartum weight retention. J Womens Health 2003;12:991-8.

22 He S, Allen JC, Razali NS, et al. Are women in Singapore gaining weight appropriately during pregnancy: a prospective cohort study. BMC Pregnancy Childbirth 2019;19:290.

23 Brouwers MC, Kho ME, Browman GP, et al. Agree II: advancing Guideline development, reporting, and evaluation in health care. Prev Med 2010;51:421-4.

24 Davenport $\mathrm{MH}$, Yoo $\mathrm{C}$, Mottola MF, et al. Effects of prenatal exercise on incidence of congenital anomalies and hyperthermia: a systematic review and meta-analysis. Br J Sports Med 2019;53:116-23.

25 Davenport MH, Nagpal TS, Mottola MF, et al. Prenatal exercise (including but not limited to pelvic floor muscle training) and urinary incontinence during and following pregnancy: a systematic review and meta-analysis. Br J Sports Med 2018;52:1397-404.
26 Barakat R, Pelaez M, Montejo R, et al. Exercise throughout pregnancy does not cause preterm delivery: a randomized, controlled trial. J Phys Act Health 2014;11:1012-7.

27 Riebe D, Ehrman JK, Liguori G, et al. Chapter 6 General Principles of Exercise Prescription. In: ACSM's Guidelines for Exercise Testing and Prescription. 10th Ed. Philadelphia, PA: Wolters Kluwer/ Lippincott Williams \& Wilkins, 2018: 143-79.

28 Beetham KS, Giles C, Noetel M, et al. The effects of vigorous intensity exercise in the third trimester of pregnancy: a systematic review and meta-analysis. BMC Pregnancy Childbirth 2019;19:281

29 Mottola MF, Davenport MH, Ruchat S-M, et al. No. 367-2019 Canadian guideline for physical activity throughout pregnancy. $J$ Obstet Gynaecol Can 2018;40:1528-37.

30 Meah VL, Davies GA, Davenport MH. Why can't I exercise during pregnancy? Time to revisit medical 'absolute' and 'relative' contraindications: systematic review of evidence of harm and a call to action. Br J Sports Med 2020;54:1395-404.

31 Mottola MF. Components of exercise prescription and pregnancy. Clin Obstet Gynecol 2016;59:552-8.

32 Sui Z, Grivell RM, Dodd JM. Antenatal exercise to improve outcomes in overweight or obese women: a systematic review. Acta Obstet Gynecol Scand 2012;91:538-45.

33 da Silva SG, Ricardo LI, Evenson KR, et al. Leisure-time physical activity in pregnancy and maternal-child health: a systematic review and meta-analysis of randomized controlled trials and cohort studies. Sports Med 2017;47:295-317.

34 Starling AP, Brinton JT, Glueck DH, et al. Associations of maternal $\mathrm{BMI}$ and gestational weight gain with neonatal adiposity in the healthy start study. Am J Clin Nutr 2015;101:302-9.

35 International Weight Management in Pregnancy (i-WIP) Collaborative Group. Effect of diet and physical activity based interventions in pregnancy on gestational weight gain and pregnancy outcomes: meta-analysis of individual participant data from randomised trials. BMJ 2017;358:j3119.

36 Muktabhant B, Lawrie TA, Lumbiganon P, et al. Diet or exercise, or both, for preventing excessive weight gain in pregnancy. Cochrane Database Syst Rev 2015:Cd007145.

37 Choi J, Fukuoka Y, Lee JH. The effects of physical activity and physical activity plus diet interventions on body weight in overweight or obese women who are pregnant or in postpartum: a systematic review and meta-analysis of randomized controlled trials. Prev Med 2013;56:351-64

38 Jaque-Fortunato SV, Wiswell RA, Khodiguian N, et al. A comparison of the ventilatory responses to exercise in pregnant, postpartum, and nonpregnant women. Semin Perinatol 1996;20:263-76.

39 Davenport MH, Skow RJ, Steinback CD. Maternal responses to aerobic exercise in pregnancy. Clin Obstet Gynecol 2016;59:541-51.

40 Pernoll ML, Metcalfe J, Schlenker TL, et al. Oxygen consumption at rest and during exercise in pregnancy. Respir Physiol 1975;25:285-93

41 Knuttgen HG, Emerson K. Physiological response to pregnancy at rest and during exercise. J Appl Physiol 1974;36:549-53.

42 Mottola MF, Davenport MH, Brun CR, et al. VO2 peak prediction and exercise prescription for pregnant women. Med Sci Sports Exerc 2006;38:1389-95.

43 Davenport $\mathrm{MH}$, Charlesworth S, Vanderspank D, et al. Development and validation of exercise target heart rate zones for overweight and obese pregnant women. Appl Physiol Nutr Metab 2008;33:984-9.

44 Wang S-M, Dezinno P, Maranets I, et al. Low back pain during pregnancy: prevalence, risk factors, and outcomes. Obstet Gynecol 2004:104:65-70.

45 Pivarnik JM. Cardiovascular responses to aerobic exercise during pregnancy and postpartum. Semin Perinatol 1996;20:242-9.

46 Ouzounian JG, Elkayam U. Physiologic changes during normal pregnancy and delivery. Cardiol Clin 2012;30:317-29.

47 Sanghavi M, Rutherford JD. Cardiovascular physiology of pregnancy. Circulation 2014;130:1003-8.

48 Morton MJ. Maternal hemodynamics in pregnancy. In: Artal R, Wiswell RA, Drinkwater BL, eds. Exercise in pregnancy. 2nd ed. Baltimore: Williams and Wilkins, 1991

49 Canadian Society for Exercise Physiology. PARmed-X for pregnancy 2015.

50 Riebe D, Franklin BA, Thompson PD, et al. Updating ACSM's recommendations for exercise Preparticipation health screening. Med Sci Sports Exerc 2015;47:2473-9.

51 Carmichael SL, Shaw GM, Neri E, et al. Physical activity and risk of neural tube defects. Matern Child Health J 2002;6:151-7.

52 Nielsen LR, Pedersen-Bjergaard U, Thorsteinsson B, et al. Hypoglycemia in pregnant women with type 1 diabetes: predictors and role of metabolic control. Diabetes Care 2008;31:9-14. 
53 Soultanakis HN, Artal R, Wiswell RA. Prolonged exercise in pregnancy: glucose homeostasis, ventilatory and cardiovascular responses. Semin Perinatol 1996;20:315-27.

54 American Academy of Pediatrics, American College of Obstetricians and Gynecologists. Guidelines for perinatal care. 8th ed. Elk Grove Village, IL and Washington, DC: AAP, American College of Obstetricians and Gynecologists, 2017.

55 Ebner F, Wöckel A, Janni W, et al. Parachuting and pregnancy: what do we know about pregnant skydivers and the risks they are taking? Clin J Sport Med 2014;24:468-73.

56 Artal R, Sherman C. Exercise during pregnancy: safe and beneficial for most. Phys Sportsmed 1999;27:51-75.

57 Camporesi EM. Diving and pregnancy. Semin Perinatol 1996;20:292-302.

58 Clark SL, Cotton DB, Pivarnik JM. Position change and central hemodynamic profile during normal third-trimester pregnancy and postpartum. Am J Obstet Gynecol 1991;164:883-887. Erratum in: Am J Obstet Gynecol 1991;165:241.

59 Mota P, Pascoal AG, Carita Al, et al. The immediate effects on Inter-rectus distance of abdominal crunch and Drawing-in exercises during pregnancy and the postpartum period. J Orthop Sports Phys Ther 2015;45:781-8.

60 Evenson KR, Mottola MF, Artal R. Review of recent physical activity guidelines during pregnancy to facilitate advice by health care providers. Obstet Gynecol Surv 2019;74:481-9.

$61 \mathrm{~B} ø \mathrm{~K}$, Artal R, Barakat R, et al. Exercise and pregnancy in recreational and elite athletes: 2016 evidence summary from the IOC expert group meeting, Lausanne. Part 1-exercise in women planning pregnancy and those who are pregnant. Br J Sports Med 2016;50:571-89.
62 DA Silva DF, Mohammad S, Hutchinson KA, et al. Cross-Validation of ratings of perceived exertion derived from heart rate target ranges recommended for pregnant women. Int J Exerc Sci 2020:13:1340-51.

63 Salvesen Kjell Å, Hem E, Sundgot-Borgen J. Fetal wellbeing may be compromised during strenuous exercise among pregnant elite athletes. Br J Sports Med 2012;46:279-83.

64 Melzer K, Kayser B, Pichard C. Physical activity: the health benefits outweigh the risks. Curr Opin Clin Nutr Metab Care 2004;7:641-7.

65 Khunda A, Shek KL, Dietz HP. Can ballooning of the levator hiatus be determined clinically? Am J Obstet Gynecol 2012;206:246 e1-4.

66 Ceydeli A, Rucinski J, Wise L. Finding the best abdominal closure: an evidence-based review of the literature. Curr Surg 2005;62:220-5.

67 Goom T, Donnelly G, Brockwell E. Returning to running postnatal - guideline for medical, health and fitness professionals managing this population. Available: https://www.absolute.physio/wp-content/ uploads/2019/09/returning-to-running-postnatal-guidelines.pdf [Accessed 06 Feb 2021]

68 Sancho MF, Pascoal AG, Mota P, et al. Abdominal exercises affect inter-rectus distance in postpartum women: a two-dimensional ultrasound study. Physiotherapy 2015;101:286-91.

69 Rasmussen M-LH, Strøm M, Wohlfahrt J, et al. Risk, treatment duration, and recurrence risk of postpartum affective disorder in women with no prior psychiatric history: a population-based cohort study. PLoS Med 2017;14:e1002392.

70 Cary GB, Quinn TJ. Exercise and lactation: are they compatible? Can J Appl Physiol 2001;26:55-75. 